1. De mechanisatie van de administratie bchoort tot het terrein van den accountant.

2. Wannecr de aceountant bij de mechanisatic leiding wil geven, is het noodig, dat hij een grondige kemnis van de moderne arbeidsmethoden en moderne hulpmiddelen bezit.

3. De groote verscheidenheid der moderne hulpmiddelen en de nog dagelijks plaats vindende veranderingen maken het den aceountant echter buitengewoon mocilijk dit gelbied to beheersehen.

4. Wel kim men vrij gemakkelijk een zekere algemeene kennis over de moderne hulpmiddelen krijgen. 1)e\%o kennis is echter voor de practische invoering en toepassing dezer hulpmiddelen onvoldoende.

5. Dit gemis tracht men in het algemeen an te vullen loor bij het nitwerken der problemen de hulp van één of meer kantoormachine-handelaren in te roepen. Idealal is de\%e oplossing echter niet.

6. Als gevolg van één en ancler kan men eonstatecren, dat de aceountant in het algemeen op het gebied van de mechanisatic nog niet de plaats inneemt, die hem overeenkomstig lyet in punt 1 gestelde toekomt.

7. Reels tien jaar geleden zijn pogingen gedaan dit envel cloor het oprichten van een centraal advies. bureau op te heffen.

8. 'Tot nog toe is daarvan cchter om versehillende redenen nog niets gekomen. II et belangrijkste bezwalar lag wel in de kosten, die de voorgestelde organisatie voor het Tnstituut zou veroorzaken.

9. Door tal vam accountants wordt cen advicsbureau echter nog steeds wensehelijk geacht.

10. Door specialisatic kan in deze behoefte worden voorzien.

I)at hot lang gewenseht orgalan thans gekomen is, mag een verblijglende gebeurtenis worden genoemd on als wij hier den initiatiefnener gelukwenschen met zijn onderneming, dan is dit in de cerste plaats in do overtuiging, dat het accountantsberoep met zijn werk wezenlijk kan worden gebaat.

C. V.

\section{UIT DE FINANCIEELE HUISHOUDING DER OVERHEID}

Red.: J. H. TEXTOR

(Bijdragen en mededeelingen zende men aan den Secretaris der Redactie)

\section{Taxatie bij grondbedrijven.}

I.

De omstancligheid, dat in dezen tijal van depressie de waarde van gronden in het algemeen daalt, plaatst vele gemeenter, die er uit hoofde van verschillende crisisomstandigheden werkloosheidszor'o, dalende helastingen enz. - financiee? toch al niet gunstig voorstaan, veclal voor groote moeilijkheden. Wij hebben hier het oog op die gemeenten, die het financieel beheer dier gronden, welke in het algemeen voor. belooluing zijn hestend, afzonderlijk hebben geregeld door daarvoor een grondhedrijf in te stellen. Ileeft bij de instelling over dit bedrijf dikwijls ook de bedocling voorgezeten om de gemeente financied nict in aroote mocilijkheklen te brengen. in den tegenwoordigen tijd blijkt lhet grondbedrijf veelal juist het tegendeel te veroolzaken van wat in den aanvang werd beoogd. Dit is een gevolg van de veiligheidsbepaling, die in de meeste verordeningen op liet beheer van dat hedrijf is vastgelegd, 11.l., dat de gronden cens in de vijf jaren moeten worlen getaxeerd en dat het nadeelig verschil, dat dan tus. schen de boekwarle en de taxatiewa arde dier gronden blijkt te bestaan, door de gemeente uit hare gewone middelen moet worden gedekt, voor zoover de bij het bedrijf gevormde reserves daartoe niet voldoende zijn. Gelukkig die gemeenten, die now den tijd heblen met taxeeren! Vele zijn dit echter niet, gerien den hierbovengenoenden termijn van vijf jaren en den tijd, gedurende welken de invloed vall de erisis merkbaar is.

In de hierroor vermelde omstandigheid en het feit, dat onlangs een interessant proefschrift aan de grondpolitiek dor Gemeente Amsterdam werd gewijd ${ }^{1}$ ), vinden wij de vrijheid om voor dic lezers, die net den financieelen kant van de gemeentelijke arondpolitiek niet op de hoogte zijn, hierna eene behandeling te laten volgen van de financiering der gemeentelijke grondbedrijven, warbij wij, na eene algemeene besprekine dier hedrijven, speciaal aandacht zullen wijden aan de genoende moeilijkheden en de wijzen, waarop men deze tracht (met den nadruk op dit woord) te ondervangen.

De uithreiding van de bevolking on als gevolg darvan de toenemende bebouwing stelden de gemeenten voor de vraag, op welke wijze het hest kon worten voorzien in eene zoodanige stadsuithreiding, dat hygienische en andere belargen niet zouden worden verwaarloosd. IIet is duidelijk, dat van het particulier initiatief alleen niet kon worden verwacht, dat met al deze vitale helangen genoegzam rekening zou worden gehouden. Men denke bijv. aan het vrijhouden van terreinen voor bouw van arbeiderswoningen, plantsoenes, scholen, e.d. Fen gemeentelijk uithreidingsplan verschaft in dit opzicht geen voldoenden warrborg, zoodat grondaankoop door de gemeente voor de hand lag. Daarbij komt, dat, indien de onemte voldoencle bouwrijpen grond voor uithreiding tot hare beschikling heeft, de waardevermeerdering, die van do bouwplannen het gevolg is, niet in handen valt van particuliere grondspeculanten maar van de gemeenschap. Wel is hierloij echter te bedenken, dat de overheid dan de taak van de speculanten overneemt met alle risico's van dien, gelijk thans maar al te vaak blijkt.

Fen grondpolitiek, die wordt gevoerd, zooals hierboven is aangegeven, eischt echter een groote som gelds. Daar de gemeenten in het algemeen niet over veel vrij kapitaal beschikken, zullen de noodige middelen, die roor aankoop en bouwrijp maken van gronden noodig zijn, uit lecningen moeten worden gevonden.

Filk jaar zal van deze leeningen een gedeelte moeten worden afuelost; olk jaar zal de gemente tevens voor de noodzakelijkheid plaatsen om de rente der geleende gelden te voldoen. Feitelijk is de financiering nit leeningen voor de gemeente terzake van haar grondpolitiek niet de meest aangewezene; zij zou zich kapitaal noeten verschaffen onder de voorwarde om af te lossen, indien de grondverkoopen dit zouden veroorlooven of, voor zoover zij zich voorstelt om de bouwrijpe gronden later in erfpacht uit te geven, zelfs zonder de verplichting tot aflossen. Afgezien van de moeilijkheden, die eene dergelijke wijze van kapitaalverschaffing voor de overheid overigens wellicht zou meebrengen (in ieder geval zou niet een zoo groot fonds ter beschikling staan), is deze wijze van financieren practisch niet mogelijk, nu bij Koninklijk Besluit van 17 Augustus 1917 (No. 78) is beslist, dat een hesluit van

1) Dr.. G. Th. J. Delfgauw, De Grondpolitiek van de Gemeente $\Lambda$ msterdam 
Gedeputeerde Staten, wartegen een gemeentehestuur bij de Kroon in heroep was gekomen, terecht de goedkeuring aan een raadshesluit onthicld, ondat in dit besluit niet was opgcnomen cene regeling betreffende ecne an te wane geldleening in dien zin, dat een regelnatige aflossing, die na cen hepaald aantal jaren zou zijn voltooid, was gewaarborgd.

De aflossing en de rentebetaling platsen de gemeente dus voor wroote moeilijkheden, temcer omdat de gronden gedurende het tijklperk ran het houwrijp maken in het algemeen weinig inkomsten opleveren (enkele huursommen uitgezonderdd). Daar de aflossingen en de rente op den gewonen dienst vall de gemeentebegrooting drukien, zouden dus van het tegenwoordige geslacht groote opofferingen worden geeischt ten hate van diegenen, die later van de grondpolitiek zullen profitecren. Ofschoon wij tegenover het vraagstuk van kapitalvorning door de overheid niet gehecl afwijzend staan - daartegen gaan echter ook vele stemmen op - brengen wij toch naar voren, dat een druk, gelijk een grondpolitiek op eenigszins ruime sehaal meehrengt, het tegenwooldig geslacht er van zou weelhouden om die matregelen te nemen, welke in het belang der stadsuitbreiding noodig zijn, ware het niet, dat het mogelijk was on dezen druk naar den kapitanldienst over te hevelen.

Naar het wellicht niet velen bekend is, heeft de gemeente Amsterdam cvenwel, als een van de weinige gemeenten in dit opricht, gredurende een lange reeks van jaren niet alleen de rente naar ook de aflossingen op de ten behoeve van de grondpolitiek gestoten geldleeningen uit hare gewone middelen hetaald. Andere gemeenten deden dat niet en dit werd mogelijk gemaakt door het instellen van de zoogenaamde grondbedrijven, die dus niet alleen zijn opgericht om een afzonderlijk overzicht te verkrijgen van de financieele nitkomsten van de grondpolitiek, - hetgeen op zich zelf reeds een zeer dringende reden zou zijn -, maar om de finaneiering op cenc andere wijze te kumnen regelen dan in de gemeentebegrooting, als kameralistisch instrument, mogelịk is.

Indien de gemeente een grondhedrijf opricht, zijn daarop ran toepassing de regelen, die ingerolge de artikelen 252, 25.3 en 265 van de gemeentewet en ingevolge de in 1931 door de Kroon vastgestelde Begrootings- en Rekeningsvoorschriften voor de bedrijven gelden. In artikel 19 der Begrootingsvoorschriften is uitdrukkelijk vastgelegd, dat de nadeelige saldi van een grondbedrijf ten laste van den kapitaaldienst der gemeente kumnen worden geloracht, indien en voor zoover de verordening, vastgesteld krachtens artikel 252 der gemeentewet (de beheersverordening), dit toelaat.

$\Lambda 1$ \%ouden dus ook bij de gemeentebedrijven de aflossingen tot de gewone uitgaven worden gerekend - hetgeen inderdaad niet het geval is - dan zouden deze aflossingen bij het grondbedrijf, voor zoover zijj een nadeelig saldo zouden verool'zaken, ten laste van den kapitaaldienst der gemeente mogen worden gedekt.

wehter is dit voorschrift van altikel 19 voor de aflossingen nict van belang, daar deze bij de gemeentebedrijven, die ingevolge artikel 252 der gemecntewet als tak van dienst zijn aangewezen, steeds op den kapitaaldienst van het hedrijf worden geregeld, hetgeen ook juist is. I3ij hedrijven, waar wordt afgeschreven, wordt dan cen hedrag, gelijk aan de vrijgekomen middelen wegens afschrijving, ten bate van den kapitaaldienst vall het bedrijf gehracht. Bij bedrijuen, zooals het grondbedrijf, waar men op de gronden niet wenscht af te schrijven, zal deze laatste bate op den kapitaaldienst ontbreken, zoodat deze dienst een nadeclig saldo zal a anwijzen, dat t.z.t. door cene geldleening zal worden gedekt.

Deze wijze van adninistreeren leeft dus tot gevolg, dat de geneente bevrijd is van de lasten der aflossing op haar gewonen dienst. Natuurlijk zou de hovenaangegeven wijze van verantwoorden op den kapitaaldienst van het bedrijf ook vervangen kumnen worden door een verantwoording op den kapitarldienst van de gemeente, zoodat hetzelfde effect verkicgen zou worden. Daar het hier echter , regelmatige" aflossingen hetreft verzet deze wijze van verantwoorden zich tegen het nu cemmal gebruikelijke systeem bij de gemeentebegrooting en dit zal wel zoo blijven, totdat op dit punt betere inzichten hambreken, nl. deze, dat ook bij de semeentebegrooling de aflossingen in het algemeen op den kapitaldienst thuis behooren en dat zij gedekt moeten worden uit hijdmgen van den gewomen dienst, die even groot zijn als de afschrijvin. wen op de oljecten, die uit de lecningsgelden zijn hetaald, terwijl een cventueel tekort of overschot aanleiding moet geven tot nieuwe leeningen op langen of korten termiju of tot helegging van kasgelden. Ook de lecningspolitiek zou daardoor verecnvoudigd worden. Pogingen in deze richting zijo de latatste jaren wel ondernomen, maar hebben nog niet tot afdocude resultaten greleid.

Toe het ook zij, ook al zou men de aflossingen op den kapitaldicnst der gemeente kumnen regelen, men zon dan toch nog vast loopen met den rentelast en daarom vooral is het instellen van cen grondluedrijf noodzakelijk.

Tn het algemeen - en nu narleren wij een preeair punt is het toch de bedoeling on ook de op de leeningen van lict grondhedrijf rustende rente geheel of gedeeltelijk uit den kapitaaldienst te dekken, m.a.w. deze rente op de waarde vain de gronden bij te schrijven en te zijner tijd uit geldleening te hestrijjen.

Is nu deze rentebijschrijving te verdedigen?

De tot verdediging aangevoerde motieven luiden als volgt. Toeneming van de hevolking in een hepaalde gemeente is vrij zeker te verwachten. Mitsdien is uitbreiding van den woningbouw het gevolg en stijgt dus de hehoefte aan houwgrond Door middel van een uithreidingsplan en cene houwverordening is de gemeente in staat de hebouwing te leiden naar de plaats, die zij aangewezen acht en op de wijze, die zij noodzakelijk acht. De gronden, die voor behouwing zijn angewezen, zullen dus in waarde stijgen. Indien nu deze gronden in handen van de gemeente zijn. zal die stijging dus aan de gemeente ten goede komen. Tegen bijschrijving van de rente hestaat dan geen bezwar. Zou deze rente uit de gewone niddelen van de gemeente worden hetaald, dan zou het toekomstig reslacht profiteeren van do opofferingen van het huidige. Dit is niet de bedoeling; de rente moet uit de toekomstige ophrengst bij verkoop worden gedekt.

Indien dezo redeneering consequent wordt doorgevoerd dan behoeft echter niet te worlen volstaan met rentebijschrijiving alleen; behalve de kosten van ophoogingen, straataanleg e.d, die matuurlijk op de warde mogen worden bijgeschreven, kunnen nl. ook de andere kosten, die gedurende het bouwrijp maken op het bedrijf drukken, zooals salarissen voor de administratie, algemeene mkosten e.d. hij de warde worden opgeteld en uit geldleeningen worden gedekt. Inderdaad is een bepaling in dien zin in enkele bedrijisverordeningen te vinden. In het algemeen verzetten zich echter de gemeentehesturen en ook de colleges van Gedeputeerde Staten, die de bedrijfsverordeningen mocten goedkeuren, tegen eene dergelijke bepaling en wel uit een oogpunt van voorzichtigheid. Immers, het hedrag van de rente is tevoren rrijwel te overzien; de overige kosten zouden wel cens onevenpedig opgevoerd liunnen worden, temcer, daar het wel ecns moeilijk zal zịjn uit te maken. welke van deze kosten uitsluitend op het grondhedriif. mogen drukken. Zelfs gaan de meeste toezicht houdende col- 
leges $n 0 \ldots$ vereler en staan zij alleen bijschrijving toe van het bedrag der rente, voorzoover dit niet gedekt kan worden nit de inlonsten vin het bedrijf, zooals huren, pachten e.d., die gedurenden den tijd van het bouwrijp maken worden genoten. De grens val hijschrijving ligt dus ten hoogste in het bedrag der leeningsrente.

De bepaling in de begrootingsvoosschriften, hiervoor ge. noemel, dat het nadedior saldo nit den kapitaaldienst der gremeente mag worden gedekt, voor zoover de bedrijfsverordening dat toclaat, makkt de bovengenoemele beschrijving overigens niet alleen matericel mar ook formed mogelijk.

On nu te roorkomen, dat de boekwarde der gronden op) den duur foch nog zou stjgen boven hetgeen inderdaad verantwoored \%ou zijn, wordt daarenboven bijna altijal geeischt, lat in de bedrijfsverordening eene bepaling wordt opgenomen in dien zin, dat de warde der gronden, zoowel bij inbreng in let hedrijf — als zij op luet tijdstip van inbreng reeds in het hezit van de gentecnte waren - als wel ecns in de vijf jaren moct worden getaxeerd en dat een eventucel hlijkend nalcelig versehil tussehen boekwaarde en taxatiewaarde, voor zoover dit niet uit gevormele reserves kan worden gedekt, nit den gewonen dienst der gentente noet worden bijgepast en wel in de cerstvolgende vijf jaren telkenmale voor een vijfde gedeclte.

Wellie vaagstukken zich nu bij den inbreng en de taxatic kunnen voordoen en voor welke nocilijliheden de gemeenten, vooral tegenwordig, kumnen worden geplaatst, behandelen wij in cen rolgend artikel.

\section{J. II. TEXTOR}

\section{UIT HET BUITENLAND \\ Red.: CH. HAGEMAN, Drs. A. TH. DE LANGE, A. IM. VAN RIETSCHOTEN en Drs. E. P. M. VAN WAES (Bijdragen en mededeelingen zende men an den Secretaris der Redactie)}

\section{Directors and public control}

Cnder bovenstainden titel komt in ,The Certified Accounfants Journal" van Maart 1935) cen artikel voor, gewijd aan de eischen, welke dienen te worden gesteld aan commissarissen (.directors") van publieke vennootschappen, opdat de belangen van de aandeclhouders voldocnde zullen worden behartigrl.

Schrijver begint met het vraagstuk meer algemeen te stellen door crop te wijzen, dat do organisatic van het bedrijfsleven in vennootschappen makt, dat zekere functionarissen moeten bestaan, die tot taak hebben ervoor te zorgen, dat publieke vemootschappen aan de spaarders een veilige belegging hunner gelden verschaffen. Dit vraagstuk krijgt vooral zijn beteekenis, doordat de aandeelen in den regel niet in handen zijn van zecl' vermogende enkelingen, maar het bezit van een zeel' groot aantal kleine spaarder's uitmaken. Door deze omstandigheden necmt de rerantwoor(clijkheid van den contrôleerenden accountant belangrijk toc. Daarom is er tevens alle reden te onderzocken, of de organisatic van de publicke vemnootschappen in het algemeen inderdaad zoodanig is, dat de belangen van de andeelhouders veilig gesteld zijn, dan wel of - zoonoodig wettelijk voorgeschreven - reorganisaties gewenscht zijn om zulks te bereiken.

In dit verband wordt gewezen op het herhaldeljik voorkomende versehịnsel, dat bij ingetreden insolventie der vennootschap de andcelhouders allepeerst vragen, wanrom zij niet tijdig door de commissarissen of door den accountant gewaarschuwd zijn voor het naderende gevaar. Naar het oordecl van den schrijver kan er evenwel niet vaak genoeg de nadruk op worden gelegd, dat de bedrijfspolitick wordt bepald door de commissarissen en nict door den accountant. Stereds weer trachten de andeelhouders den accountant tekortkomingen te verwijten, welke in warheid den commissarissen moeten worden aangeschreven, terwijl de commissarissen deze afschuiving van de verantwoordelijkheid sterk bevorderen. Ook onder de conmissarissen onderling tracht men voortdurend de verantwoordelijklieden van elk humner te verwar'ren.

Indien men aldus de commissarissen een specifick eigen verantwoordelijkheid wil laten dragen, is het volgens selurijuer vanzelfsprekend, dat men ook ecrige eischen stelt aan de capaciteiten dier functionarissen. Kooals de wetgever voor de uitocfening van de jurjolische en medische beroepen bepadale regels heeft gesteld, zooals de accountants door mirldel vam hun organisaties hum eigen heroepswoorschriften hobben vast gresteld, zoo dienen ook aan de commissarissen van publicke vennootschappen beparalde eischen te worden gesteld. Alle drie groepen van functionarissen werken in het publieke belang; het publick dient dan ook van cen gocde nitocfening dier functics verzekerd te zijn. ,The publie has been trained, even in advance of legislation, to demand skill of an ascertainable standard from those who are to audit accounts or to act in consultative (but subordinate) capacities to directors of companics; but neither legislation nol public opinion has hitherto been directed towards the achievement of a state of affairs when the directol's themselves shall exhilit the specialised skill which their occupation would seem to neeessitate; and, after all, when a company's finanees have been endangered or sunk it is the directors who have driven the vessel into such a position, whilst the accountancy profession is simply allowed to deal with the wreckage."

Het is niet de bedoeling van den schrijver aan te dringen op de instelling van een examen voor commissarissen, zoodat de aandeelhouders hun vertrouwensmammen zouden moeten kiezen uit leden van ,associations of duly qualified dircetors." Wel acht hịj het mogelijk en gewenscht regels op te stellen, volgens welke, a person who comes forward to discharge the public function of directing a public company slall in some way manifestly appear to have justification for so doing." Het is te betrenren, dat de schrijver in zijn artikel nalaat een - zij het algemecne - formulecring te geven van die cischen van bekwaamheid voor commissaris; het schijnt zelfs, dat dic bekwamheid roor den sehrijver niet in de cerste plaats moet worden gezocht in de richting van kcmis van het bedrijfsleven, maar in allerlei persoonlijke omstandigheden. Zoo wordt verlangd, dat de candidaat-commissaris zal mededeclen ,particulars relating to his personal qualifieations and experience and the number of other boards amongst which he distributes his energies." Vooral dit laatste acht schijuver van belang; van andere functionarissen in een vemnootschap, die cen veel minder vool'name positie innemen, verlangt men volledige toewijding; $\mathrm{er}$ is nog meer reden dit te verlangen van de allerhoogste functionarissen. „For such in vely truth the directors of a company arc; too often they are allowed to forget that they are the servants of their member's". Naar de schrijver meent, zijn de aandeelhouders in dit opzicht ook in gebreke, doordat zij niet voldoende hun invloed doen gelden op andeelhoudersrergaderingen. Het zou gewenseht zijn deze vergaderingen te houden op tijden, dat ook de kleine bezitters aanwezig kunnen zijn. Bij groote vemootschappen zou om practische redenen een systeem van vertegenwoordiging noodig kunmen blijken. Maar in icder geval dienen de ,directors" dan ook te zorgen, en de wet zou hier dwingend kunnen voossehrijven, dat aan de aandeelhouders meer inlichtingen worden verschaft, dan thans 